\title{
Association between Neighborhood Built Environment and Body Mass Index among Chinese Adults: Hierarchical Linear Model
}

\author{
Mengqi Zhong, Tongji University; China \\ Yuanyi Shen, Tongji University; China \\ Yifan Yu, Tongji University; China
}

\begin{abstract}
Obesity is becoming a global health problem. With the living standards of residents have improved rapidly in China, the problem of obesity becomes a serious threat to people's health. Although obesity effected by many factors, the role of the built environment in relation to obesity among population should be taken into consideration. This paper examines the association of built environment and body mass index with the hierarchical linear model, based on the data from 2016 China Labor-force Dynamics Survey (CLDS), which involves 29 provinces in China and investigates 401 villages or communities as well as 14226 families. In this paper, the village or community is used as the basic analysis unit, and the body mass index of the residents is used as the dependent variable, and neighborhood built environment (e.g. density of exercise facilities, square or park and distance to them) is as independent variables, socioeconomic status (e.g. age, gender, education, marital status, income and employment status) and health and exercise characteristics (e.g. self-rated health, average weekly exercise time and frequency) are as control variables. Participants are adults aged 15-65 years $(n=21086$; $63.30 \%$ rural vs urban). With the independent variables from both individual and residential levels, hierarchical linear model is applied respectively to examine how body mass index is affected. Additionally, samples are classified by age group, urban/rural neighborhood and we figure out which factor mainly effected different groups. We explore that BMI is higher in high- vs. low-facility density neighborhoods but not significantly differ by neighborhood income. Overweight/obesity (BMI >= 25) is lower in high-developed districts. Physical fitness is higher in high-income neighborhoods but unrelates income. We conclude that living in walkable neighborhoods is associated with more physical activity and lower overweight/obesity but not with other benefits. Adults in higher-income neighborhoods have lower BMI and higher mental condition. These findings have important implications for urban planning and the corresponding improvement strategy is proposed.
\end{abstract}

\section{Keywords}

body mass index, health facilities, built environment, hierarchical linear model 


\section{Introduction}

\subsection{Background}

Obesity rates have been rising globally in recent decades. According to the World Health Organization, more than one in ten people in the world are now classified as obese (WHO,2013). Nowadays, obesity is considered as one of the most important medical and public health issues of our time (Ells L \& Cavill N, 2009). Obesity can be measured in various ways. Body mass index (BMI) is the most commonly used measure of assessing obesity in adults. (A Must and SE Anderson, 2006). BMI is used not only for assessing weight at the individual level, but also at population level assessment for its measurement method is very convenient and practical. Based on individual height and weight, BMI is calculated as weight in kilograms divided by the square of height in meters.

$$
\mathrm{BMI}=\frac{\text { weight }(\mathrm{kg})}{\text { height }(\mathrm{m})^{2}}
$$

\subsection{The danger of obesity}

Many studies have investigated how BMI contributes to the morbidity and mortality of various related diseases. BMI as a measure of unhealthy weight and related diseases in the population, different studies using statistical methods to analyze it may help to determine the correlation between obesity, health characteristics and influencing factors. Epidemiological studies have shown that people with very high BMI have a high risk, such as severe $(\geqslant 35 \mathrm{~kg} / \mathrm{m} \mathrm{2}$ ) or morbid ( $\geqslant 40 \mathrm{~kg} / \mathrm{m} \mathrm{2}$ ) obesity (CM Kitahara, 2014), and underweight will increase its morbidity and mortality. Both overweight and obesity are associated with the incidence of multiple comorbidities including type II diabetes, cancer and cardiovascular diseases, which can pose a threat to people's health and place a heavy burden on the health care system. Maintaining a healthy weight is important in the prevention of the large disease burden in the future. (Daphne P Guh et al., 2009).

\subsection{Influencing factors of BMI}

BMI is affected by many factors. In 1989, Sobal and Stunkard (1989) first studied the relationship between socioeconomic status (SES) and obesity. The understanding and pursuit of attributes that are valued in developed societies, such as healthy and lean bodies, people in higher socioeconomic groups tend to have a healthier diet. Meanwhile, education may also mean expectations of individual achievement, whether in general or health, weight and appearance. Studies have shown that it is reasonable for high-educated women to favor the pursuit of thin attributes. (McLaren L, Kuh D, 2004). Women in low- medium human development index countries have the most common positive correlation between SES and body size.

In the context of urban planning, some scholars pay attention to the relationship between built environment and BMI. Access to physical activity facilities is the most common measure of the built environment. Urban construction environments, including parks and other green spaces, and recreational projects that provide structured settings for sports, may also create opportunities for physical activity that affect the increase of obesity (Jennifer Wolch et Al., 2011). Hoehner et al. (2013) found that the characteristics of the built environment around the home and workplace may affect the BMI, and the increase in recreational facilities 
(exercise facilities and parks) can decrease the individual's BMI, which may increase the exercise opportunities of residents due to the increased facilities. Giles-Corti B, Macintyre $S$, Clarkson J, et al (2003) calculated the distance between the study participants' homes to the nearest recreational facility, showing a positive correlation between the distance from the nearest facility and the increased risk of overweight. Gordon-Larsen P, Nelson MC, Page P, et al (2006) found that there is a positive correlation between the number of recreational facilities and the likelihood of being overweight. Mobley LR, Root ED, Finkelstein EA, et al (2006) found a significant negative correlation with BMI using density measurements (the number of fitness facilities per 1,000 inhabitants, in the postal code).

\section{Methodology and data}

\subsection{Methodology}

In the social sciences, we have variables that describe individuals. The group consisting of individuals also has a series of variable descriptions. In this case, the data structure has a stratification phenomenon. Ordinary linear models are difficult to measure data on two levels, so a hierarchical linear model is chosen.

Hierarchical linear modeling allows the data to be structured in at least 2 levels. In this model, the first level is the repeated measure (time or condition) nested within the second level, which is the person-level data (Raudenbush SW, Bryk AS, 2007). The first level captures the within-subject variation, whereas the second level describes the between-subjects variability(Van Der Leeden R.,1998).

In practical application, the regression equation is built with the first-level variables, and then the intercept and slope in the equation are used as the dependent variables, while the variables in the second-level data are used as the independent variables. Then two new equations are established. Through this process, the influence of different level variables on the dependent variable can be explored.

\subsection{Data}

The data used in this paper is from the China Labor-Force Dynamic Survey conducted by the Center for Social Survey (CSS), Sun Yat-sen University in 2016. The survey uses a multi-stage, multi-level probability sampling method, which is proportional to the size of the workforce. The survey conducted a biennial tracking of urban and rural villages in China, and established a comprehensive database of labor force surveys, including three levels of tracking and cross-sectional data of individual labor, family and community. Its content covers migration, education, work, health, social participation and other information. At present, the CLDS has included the 2011 Guangdong Provincial Trial Survey, the 2012 National Baseline Survey, the 2014 Tracking Survey, and the 2016 Tracking Survey. The 2016 CLDS survey was conducted in 29 provinces, municipalities and autonomous regions across the country (excluding Hong Kong, Macao, Taiwan, Tibet, and Hainan). A total of 401 village community questionnaires, 14226 family questionnaires, and 21086 individual questionnaires for 15-64 labor force populations were completed. After deleting the samples with missing data values, a total of 12,648 samples from 374 village neighborhood committees were obtained for analysis. 


\subsection{Measures}

\section{Individual-level independent variables}

In the individual-level, the study includes variables such as individual socioeconomic attributes, self-reported health, and exercise status. We transform the descriptive variables into dummy variables for analysis.

Table 1 Individual-level independent variables

\begin{tabular}{|c|c|}
\hline Variable & Definition \\
\hline UNITTYPE & 1:community; 0:village \\
\hline GENDER & 1:female; 0:male \\
\hline AGE & in years \\
\hline MARRIAGE & 1:married;0:otherwise \\
\hline \multirow[t]{3}{*}{ EDUCATION } & 1:elementary school and below \\
\hline & 2:middle school \\
\hline & 3:university and above \\
\hline INCOME & total income in 2016 \\
\hline EMPLOYME & 1:employed; 0:otherwise \\
\hline \multirow[t]{5}{*}{ HEALTH } & 1:very bad \\
\hline & 2:bad \\
\hline & 3:moderate \\
\hline & 4:good \\
\hline & 5:very good \\
\hline WHETHER EXERCISE & 1:yes; 0:no \\
\hline \multirow[t]{5}{*}{ EXERCISE TIME } & 1:0min \\
\hline & 2:1-150min \\
\hline & $3: 150-500 \mathrm{~min}$ \\
\hline & 4:500-1000min \\
\hline & 5:over 1000min \\
\hline
\end{tabular}

\section{Neighborhood-level independent variables}

In the neighborhood-level, we mainly use the density of exercise facilities and parks/squares in the neighborhood unit as well as the frequency of use of these facilities as independent variables. This paper argues that the density of recreational facilities and the atmosphere of physical activity can affect the physical activity of the residents and futher affect their BMI. 
Table 2 Neighborhood-level independent variables

\begin{tabular}{ll}
\hline Variable & Definition \\
\hline Exercise facilities density & $=$ quantity / area \\
\hline Park/square density & $=$ quantity / area \\
\hline Frequency of use of exercise facilities density & $1-5:$ frequency from less to more \\
\hline Frequency of use of park/square & $1-5:$ frequency from less to more \\
\hline
\end{tabular}

\section{Outcome variables}

We use BMI as the dependent variable, and the BMI is calculated by height and weight. The obtained BMI is divided into 5 levels according to WHO standards. The current WHO BMI cut-off points of $<16.0 \mathrm{~kg} / \mathrm{m} 2$ (severe underweight), $16.0-18.49 \mathrm{~kg} / \mathrm{m} 2$ (underweight), 18.5$24.9 \mathrm{~kg} / \mathrm{m} 2$ (normal range), $\geqslant 25$ (overweight), $25-29.9 \mathrm{~kg} / \mathrm{m} 2$ (preoboese), $\geqslant 30 \mathrm{~kg} / \mathrm{m} 2$ (obesity). (WHO Expert Consultation, 2004).

Table 3 Outcome variables

\begin{tabular}{lll}
\hline BMI & Definition & nutritional status \\
\hline $\mathbf{1}$ & $<16.0$ & severe underweight \\
\hline $\mathbf{2}$ & $16.0-18.49$ & underweight \\
\hline $\mathbf{3}$ & $18.5-24.9$ & normal range \\
\hline $\mathbf{4}$ & $25.0-29.9$ & Preoboese \\
\hline $\mathbf{5}$ & $\geqslant 30.0$ & obesity
\end{tabular}

\section{Data analysis}

\subsection{Model}

We build models based on the above conditions. The model is as follows:

Level-1 Model

$Y=B 0+B 1^{*}\left(\right.$ UTYPE201) $+B 2 *($ GENDER $)+B 3^{*}(A G E)+B 4^{*}($ MARRIAG $)+$ $B 5 *(E D U C A T I O N)+B 6^{*}(I N C O M E)+B 7^{*}(E M P L O Y M E)+B 8^{*}(H E A L T H)+B 9 *($ WHETHER EXERCISE) + B10*(EXERCISE TIME) + R

Level-2 Model

$$
\begin{aligned}
& \mathrm{B} 0=\mathrm{G} 00+\mathrm{U} 0 \\
& \mathrm{~B} 1=\mathrm{G} 10 \\
& \mathrm{~B} 2=\mathrm{G} 20 \\
& \mathrm{~B} 3=\mathrm{G} 30
\end{aligned}
$$




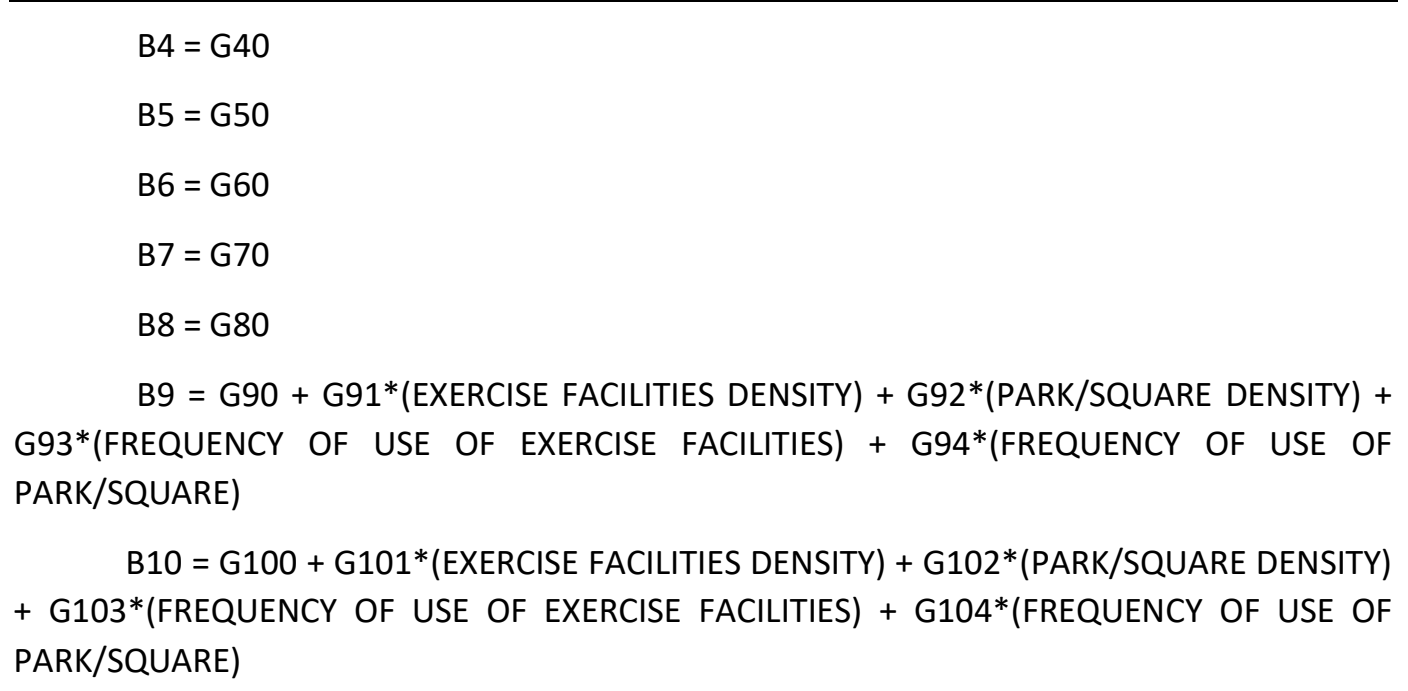

\subsection{Analytic strategy}

First, we establish a stochastic regression model of the first level of variables. Based on the significance test results of the first-level variable regression analysis, we determine whether the difference of the first level of variables on the second level is significant. If the difference is significant, we will select the variables on the second level to establish a regression model for further analysis. This paper uses HLM 6.08 software to run the hierarchical linear model.

\section{Result}

Descriptive statistics are provided in Table 4. Of all the samples, 33.6\% are urban residents and $66.4 \%$ are rural residents. $83.8 \%$ of them are women and $16.2 \%$ of them are men. $86.9 \%$ samples are married while $13.1 \%$ samples are otherwise. $0.5 \%$ of people are severe underweight, $6.4 \%$ of people are underweight, $67.6 \%$ of people are normal range, $22.3 \%$ of people are preoboese, and $3.1 \%$ of people are obesity.

Table 4 Descriptive statistics for dependent and independent variables

\begin{tabular}{llllll}
\hline VARIABLE NAME & $\mathbf{N}$ & MEAN & SD & MINIMUM & MAXIMUM \\
\hline Individual-level & & & & & \\
\hline UTYPE & 12648 & 0.34 & 0.47 & 0 & 1 \\
\hline GENDER & 12648 & 0.84 & 0.37 & 0 & 1 \\
\hline AGE & 12648 & 45.63 & 12.83 & 16 & 96 \\
\hline MARRIAGE & 12648 & 0.87 & 0.34 & 0 & 1 \\
\hline CENUSACC & 12648 & 1.41 & 0.83 & 1 & 5 \\
\hline EDUCATION & 12648 & 3.64 & 2.35 & 1 & 11 \\
\hline INCOME & 12648 & 33658.48 & 61158.56 & 100 & 305000 \\
\hline EMPLOYMENT & 12648 & 4.25 & 1.16 & 1 & 10 \\
\hline
\end{tabular}




\begin{tabular}{llllll}
\hline HEALTH & 12648 & 3.66 & 0.96 & 1 & 5 \\
\hline WHETHERE & 12648 & 0.29 & 0.45 & 0 & 1 \\
\hline EXERCISE TIME & 12648 & 1.5 & 225.46 & 0 & 5130 \\
\hline BMI & 12648 & 4.2 & 0.87 & 1 & 5 \\
\hline Neighborhood-level & & & & \\
\hline EXERCISE FACILITIES DENSITY & 374 & 9.54 & 91.17 & 0 & 1666.67 \\
\hline PARK/SQUARE DENSITY & 374 & 5.77 & 86.29 & 0 & 1666.67 \\
\hline FREQUENCY OF USE OF EXERCISE FACILITIES & 374 & 2.54 & 1.98 & 0 & 5 \\
\hline FREQUENCY OF USE OF PARK/SQUARE & 374 & 1.79 & 2.17 & 0 & 5 \\
\hline
\end{tabular}

We use a hierarchical linear model to analyze the impact of the built environment on BMI, which is done in several steps. Step one, we run the empty model and get the variance within the group is 0.35851 while the variance between groups is 0.02972 . $\operatorname{ICC}(1)=0.076552>0.059, \quad \operatorname{ICC}(2)=0.703>0.7$. So, this data is suitable for HLM analysis. Step two, we put the level-1 variable into the model and get the model1. Step three, we put the level-1 and level-2 variables together into the model to get the model2. Results are provided in Table 5.

Table 5 Multi-level analysis of community environments on labors' BMI

\begin{tabular}{lcccccc}
\hline & Model 1 & & & Model 2 & \\
& Coefficient & error & P-value & Coefficient & error & P-value \\
\hline Fixed effects & & & & & & \\
\hline Grand intercept & 2.99215 & 0.04772 & 0.000 & 3.000756 & 0.047852 & 0.000 \\
\hline Individual-level predictors & & & & & \\
\hline Unit type & & & & & \\
\hline Gender & 0.051985 & 0.021476 & 0.016 & 0.042277 & 0.021951 & 0.054 \\
\hline Age & 0.077455 & 0.017339 & 0.000 & 0.078242 & 0.017355 & 0.000 \\
\hline Marriage & -0.0011 & 0.000586 & 0.059 & -0.00112 & 0.000585 & 0.056 \\
\hline Education & 0.119835 & 0.01864 & 0.000 & 0.120478 & 0.018695 & 0.000 \\
\hline Income & -0.02543 & 0.011914 & 0.033 & -0.02453 & 0.012017 & 0.041 \\
\hline Employment & 0 & 0.000000 & 0.569 & 0 & 0 & 0.557 \\
\hline Health & -0.01415 & 0.005325 & 0.008 & -0.01385 & 0.005312 & 0.010 \\
\hline Whether exercise & 0.009358 & 0.006932 & 0.177 & 0.009107 & 0.006969 & 0.192 \\
\hline & 0.012774 & 0.032231 & 0.692 & 0.017222 & 0.02876 & 0.549 \\
\hline
\end{tabular}




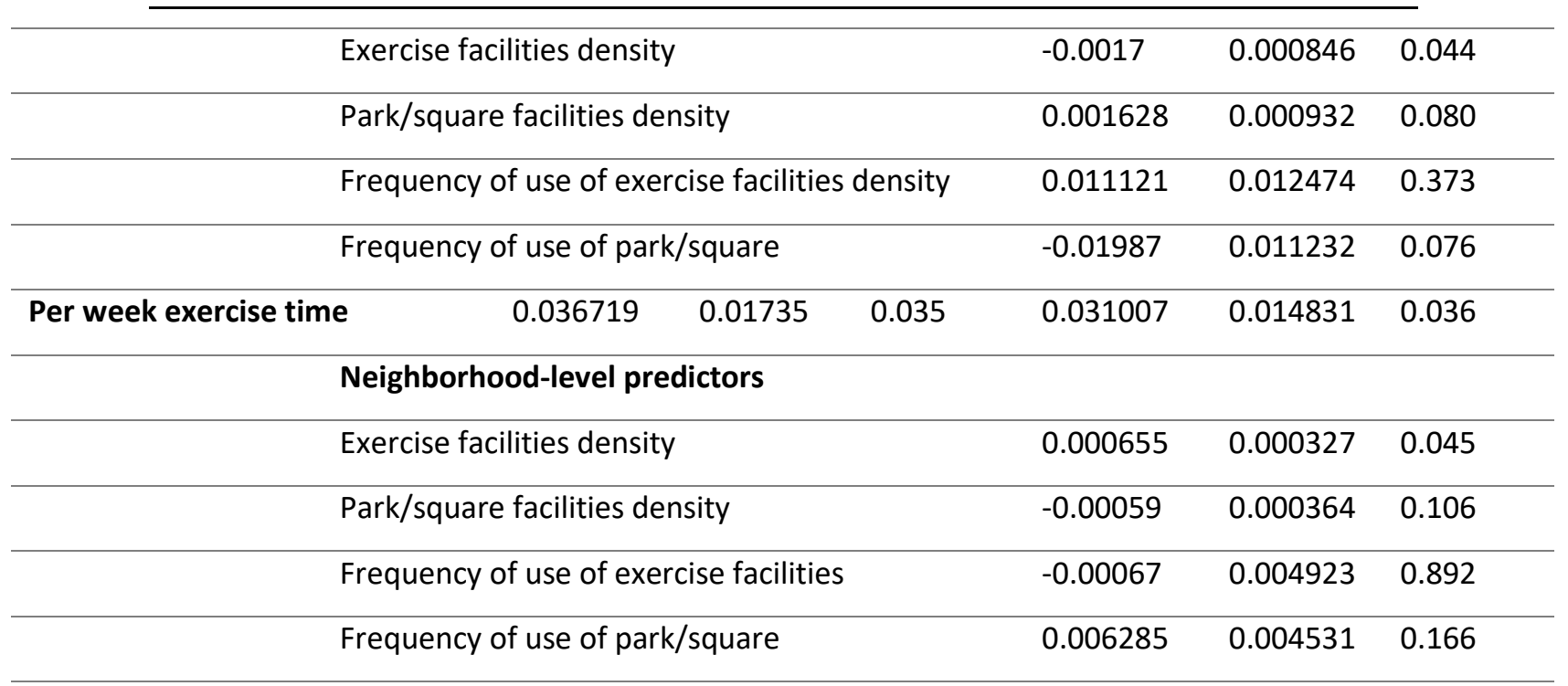

$+\mathrm{P}<0.10 ; * \mathrm{P}<0.05 ; * * \mathrm{P}<0.01 ; * * * \mathrm{P}<0.001$

First, the results of model1 are obtained. Unit type, gender, marriage, education, employment and per week exercise time are significant at the level of $P<0.05$. Unit type, gender, marriage, and per week exercise time is positively related to the result of BMI while education, employment is inversely related to the result of BMI. Further explanation is that urban units, women, married, and long-term exercisers tend to increase the level of BMI while the increase in education and work can lower the BMI level.

Next, we added the independent variables at the neighborhood level to establish the level-2 regression model to explain the differences between regions. When the regression coefficient of the level- 2 variable is the same as the coefficient symbol of the level- 1 variable, it indicates that the effect of the level- 2 variable on the level- 1 predictor is enhanced, and the direction of action is consistent with the direction of the level-1 coefficient. Conversely, the regression coefficient of the level- 2 variable is opposite to the level-1 sign, indicating that the level 2 variable has a weakening effect on the correlation of level- 1 .

This paper argues that the number of facilities and the atmosphere in the neighborhood can influence whether people exercise and their exercise time. We get the result of model2. In terms of whether people exercise, park/square facilities and frequency of use of exercise facilities have a strengthening effect on the level1 variable, and the algorithm density and frequency of use of park/square have a weakening effect on the level1 variable. Among them, the exercise facilities density is significant at the level of $P<0.05$, and the park/square facility density and frequency of use of park/square is significant at the level of $P<0.1$. The addition of the level- 2 variable increases the impact and significance of level- 1 on the BMI.

As for per week exercise time, the park/square density and frequency of use of exercise facilities have a weakening effect on the leve-I1 variable, and the exercise facilities density and frequency of use of park/square have a strengthening effect on the level-1 variable. Among them, the performance density was significant at the level of $P<0.05$. 


\section{Discussion}

Our findings are consistent with previous literature findings that indicate that individuallevel and community-level factors have an impact on residents' BMI. The study found that at the individual level, the socio-economic attributes of residents have an impact on BMI. At the community level, the community's exercise facilities, parks, squares, and the frequency with which residents use such facilities also have an impact on the individual's BMI. Our sample-level design refers to the previous literature and shows the advantages of both individual and community levels, but the impact of community-level variables on individuallevel variables still requires more research to prove.

Despite this, the study has its own limitations. Our samples come from all over China. The geographical diversity of China is quite different. The living habits and cultural traditions of residents are also quite different. Some key variables affecting BMI may not be measured.

Meanwhile, the limitations of research on the environmental impact of our health outcomes involve the complexity of measures and linkages. This is an inherent feature of the multifactorial nature of the environment, where all aspects of the community can have both positive and negative effects on health. The community environment in which residents choose to live may have been influenced by the socioeconomic attributes of themselves. Prosperous communities may be close to both parks and fast food restaurants that have a negative impact on BMI, and these complex connections are difficult to measure directly. Future research should address many of these limitations.

\section{References}

A Must and SE Anderson (2006) Body mass index in children and adolescents: considerations for population-based applications, International Journal of Obesity, Vol.30.

Christine M. Hoehner, Peg Allen, Carolyn E. Barlow, Christine M. Marx, Ross C. Brownson*, and Mario Schootman (2013) Understanding the Independent and Joint Associations of the Home and Workplace Built Environments on Cardiorespiratory Fitness and Body Mass Index, American Journal of Epidemiology, Vol.178.

CM Kitahara, AJ Flint, A Berrington de Gonzalez, et al. (2014) Association between class III obesity (BMI of $40-59 \mathrm{~kg} / \mathrm{m} 2$ ) and mortality: a pooled analysis of 20 prospective studies, PLoS Medicine, Vol.11.

Daphne P Guh, Wei Zhang, Nick Bansback, Zubin Amarsi, C Laird Birmingham and Aslam H Anis (2009) The incidence of co-morbidities related to obesity and overweight: A systematic review and meta-analysis, BMC Public Health, Vol.9 (March).

Ells L, Cavill N. (2009) Preventing childhood obesity through lifestyle change interventions, A briefing paper for commissioners. Oxford: National Obesity Observatory.

Giles-Corti B, Macintyre S, Clarkson J, et al (2003) Environmental and lifestyle factors associated with overweight and obesity in Perth, Australia. AMERICAN JOURNAL OF HEALTH PROMOTION, Vol.18. 
Gordon-Larsen P, Nelson MC, Page P, et al. (2006) Inequality in the built environment underlies key health disparities in physical activity and obesity. Pediatrics, Vol.117.

Jennifer Wolch, Michael Jerrett, Kim Reynolds, Rob McConnell, Roger Chang, Nicholas Dahmann, Kirby Brady, Frank Gilliland, Jason G. Su, Kiros Berhane (2011) Childhood obesity and proximity to urban parks and recreational resources: A longitudinal cohort study, Health \& Place, Vol. 17.

McLaren L, Kuh D. (2004) Women's body dissatisfaction, social class, and social mobility, SOCIAL SCIENCE \& MEDICINE, Vol.58.

Mobley LR, Root ED, Finkelstein EA, et al. (2006) Environment obesity, and cardiovascular disease risk in low-income women, AMERICAN JOURNAL OF PREVENTIVE MEDICINE, Vol.30.

Raudenbush SW, Bryk AS. (2002) Hierarchical Linear Models: Applications and Data Analysis Methods. 2nd ed. Thousand Oaks, CA: Sage

Sobal J, Stunkard AJ (1989) Socioeconomic status and obesity: a review of the literature., Psychol Bull, Vol.105.

Van Der Leeden R (1998) Multilevel analysis of repeated measures data. Qual Quant, Vol. 32.

World Health Organization (2013) Obesity and overweight, World Health Organization. 